\title{
Sensitivity of sea-level forecasting to the horizontal resolution and sea surface forcing for different configurations of an oceanographic model of the Adriatic Sea
}

\author{
Lidia Bressan, Andrea Valentini, Tiziana Paccagnella, Andrea Montani, Chiara Marsigli, and \\ Maria Stefania Tesini \\ Hydro-meteo-climate service, Regional Agency for Prevention, Environment and Energy of Emilia-Romagna \\ (Arpae-SIMC), Bologna, 40122, Italy \\ Correspondence to: Lidia Bressan (lbressan@arpae.it)
}

Received: 13 January 2017 - Revised: 20 March 2017 - Accepted: 28 March 2017 - Published: 12 April 2017

\begin{abstract}
At the Hydro-meteo-climate service of the Regional environmental agency of Emilia-Romagna, Italy (Arpae-SIMC), the oceanographic numerical model AdriaROMS is used in the operational forecasting suite to compute sea level, temperature, salinity and 3-D current fields of the Adriatic Sea (northern Mediterranean Sea). In order to evaluate the performance of the sea-level forecast and to study different configurations of the ROMS model, two marine storms occurred on the Emilia Romagna coast during the winter 2015-2016 are investigated.

The main focus of this study is to analyse the sensitivity of the model to the horizontal resolution and to the meteorological forcing. To this end, the model is run with two different configurations and with two horizontal grids at 1 and $2 \mathrm{~km}$ resolution. To study the influence of the meteorological forcing, the two storms have been reproduced by running ROMS in ensemble mode, forced by the 16-members of the meteorological ensemble COSMO-LEPS system. Possible optimizations of the model set-up are deduced by the comparison of the different run outputs.
\end{abstract}

Introduction

Arpae-SIMC is the weather service of the Emilia-Romagna region and provides weather warnings for the Region and for the Italian Civil Protection Department. For these activities, Arpae-SIMC runs a chain of operational meteorological, oceanographic and wave numerical models at different horizontal resolution. Additionally, it provides tools, products and indicators for the evaluation of the impacts of storms on the coast that are discussed every day by the regional task force, together with the Civil Protection Agency and the regional Geological Seismic and Soil Survey. Weather warnings are based, for coastal events, on the combined information of sea level and significant wave height: the correct forecasting of waves and sea level, which is accomplished by the operational wave and ocean models, is therefore of crucial importance for accurate marine early warnings (Harley et al., 2016).

AdriaROMS (Chiggiato and Oddo, 2008) is the oceanographic model that runs operationally at Arpae-SIMC and it is an implementation of the ROMS model (Regional Ocean Modeling System, Shchepetkin and McWilliams, 2005; Haidvogel et al., 2008) for the Adriatic Sea, in the Mediterranean (see Fig. 1). ROMS is a free-surface, terrainfollowing ocean model that solves the primitive equations of the ocean: it evolves the 3-D equations for momentum and tracers together with the equations for free surface and for the vertically integrated momentum.

With the aim to update the oceanographic model suite, a study has been carried out to evaluate and compare different ROMS implementations. Also the Coupled-OceanAtmosphere-Wave-Sediment Transport Modeling System (COAWST, Warner et al., 2010), which is a model that cou- 

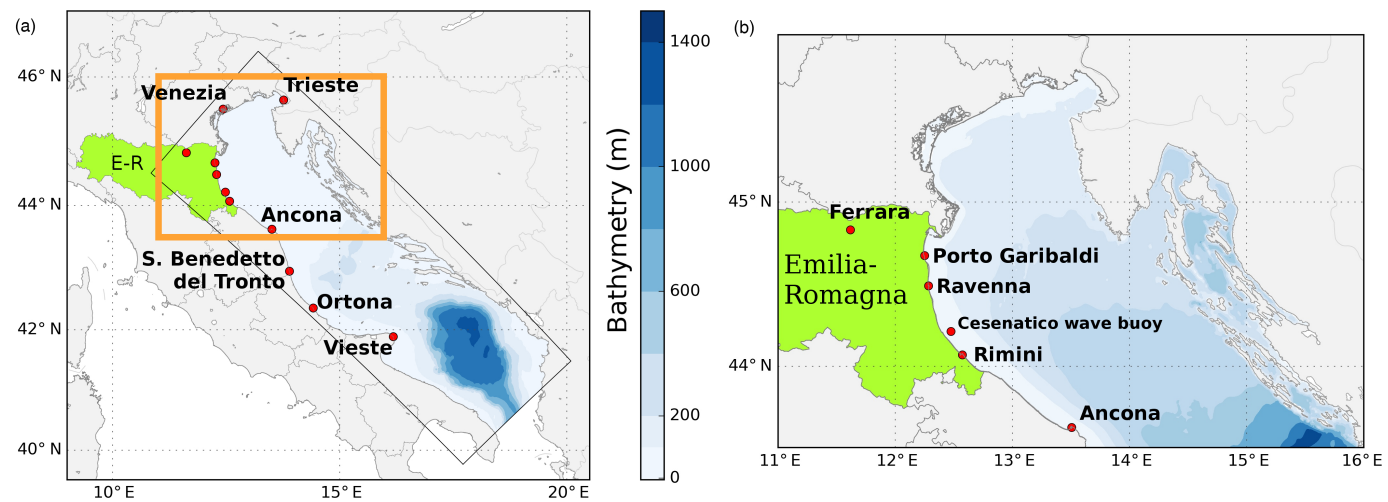

Figure 1. Computational grid and bathymetry of the Adriatic Sea (a). Zoom of the Northern Adriatic sea (b). The tide gauge stations of Vieste, Ortona, San Benedetto del Tronto, Ancona and Porto Garibaldi are indicated with red dots together with the locations of the weather stations of Ferrara, Ravenna and Rimini and the Cesenatico wave buoy.

ples an ocean-sediment model with waves and atmospheric models, is here used as a pure oceanographic model, i.e. as an alternative implementation of ROMS. This study aims to investigate the performance of the models to properly reproduce sea level in case of extreme conditions, especially during storm surge events. In this study we focus in particular on the sensitivity of the models to the horizontal resolution and to the meteorological forcing.

\section{Case studies}

Two moderate storms that occurred in the winter 2015-2016 have been analysed in this study.

The first event is a one-day event, which started in the late afternoon of the 21 November 2015 (see the event observations in Fig. 2). It is triggered by a Bora wind event, with cold winds from NE that reached about $20 \mathrm{~m} \mathrm{~s}^{-1}$ in Rimini and about $18 \mathrm{~m} \mathrm{~s}^{-1}$ in Ravenna. The maximum significant wave height $\mathrm{Hs}$ of the event was $3.3 \mathrm{~m}$, measured on the 21 November 2015 at 23:00 UTC by the Arpae wave buoy, offshore Cesenatico. Despite some missing data in the Arpae wave buoy record, it is possible to suppose a secondary peak on the morning of the following day thanks to the surge measured by the Porto Garibaldi (Ferrara) tide gauge.

The second storm, of moderate intensity, occurred in February 2016 following Sirocco winds from SE. It lasted two days, from 28 to 29 February 2016. The winds in Ravenna and in Ferrara area reached the velocity of $15 \mathrm{~m} \mathrm{~s}^{-1}$, while the maximum significant wave height was almost $2.5 \mathrm{~m}$.

\section{Models and simulations}

AdriaROMS has been running operationally at Arpae-SIMC since 2005 and it underwent a major update in 2010 (Russo et al., 2013). AdriaROMS has a regular grid with $2 \mathrm{~km}$ horizontal resolution and 20 vertical $\sigma$-levels. It is forced at the southern boundary (Strait of Otranto) by astronomical tides derived from the OTIS database (Egbert and Erofeeva, 2002) and by the oceanographic fields (salinity, temperature and currents) provided by the Mediterranean Ocean Forecasting system (MFS, Oddo et al., 2009). AdriaROMS is forced at the sea surface by the fields of the atmospheric model COSMO-I7 (namely $10 \mathrm{~m}$ wind, mean sea level pressure, $2 \mathrm{~m}$ temperature, $2 \mathrm{~m}$ relative humidity, cloud cover, precipitation rate and short-wave solar radiation). AdriaROMS includes fresh water sources of 49 rivers, of which only the Po river water flow rate is based on daily data, while for the other 48 rivers it is based on monthly climatology (Raicich, 1996).

An alternative implementation of ROMS for the Adriatic Sea has been developed within the HAZADR project (HAZADR final publication, 2015) using the COAWST system (similar to the work of Benetazzo et al., 2013), using the ROMS model only. In order to distinguish between the two different implementations of ROMS, we refer to the operational implementation of AdriaROMS as "Aop" and to the implementation using COAWST for HAZADR as "Ah". The main differences of the two implementations are the following:

1. the $\sigma$-level discretization, which follows the discretization of Shchepetkin and McWilliams (2005). The model Aop uses the stretching function described in Song and Haidvogel (1994), while Ah uses the stretching function described in Shchepetkin and McWilliams (2009);

2. the generic length scale vertical mixing implementation: the model Aop uses a $k-\omega$ parametrization after Wilcox (1988), while the model Ah uses a $k-\varepsilon$ parametrizaton, after Rodi (1987);

3. the tidal forcing, which includes diurnal and semidiurnal tidal constituents: five of Aop (O1, K1, N2, M2, S2) and eight of Ah (O1, K1, K2, N2, M2, S2, P1, Q1). 

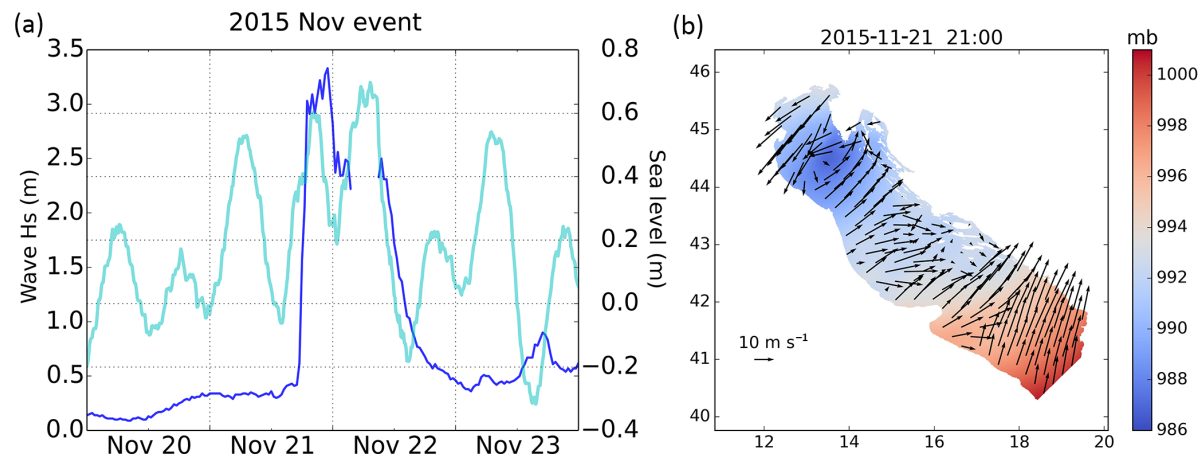

Figure 2. 21 November 2015 storm. (a) Significant wave height recorded by the Arpae wave buoy, offshore Cesenatico $\left(44.2155^{\circ} \mathrm{N}\right.$ $12.4766^{\circ} \mathrm{E}$, blue line), and sea level by the Porto Garibaldi tide gauge $\left(44.68^{\circ} \mathrm{N}, 12.25^{\circ} \mathrm{E}\right.$, light blue line). (b) Forecasted sea level pressure and wind fields at 21:00 of 21 November 2015 of the deterministic run of COSMO-LEPS (started at 00:00, 20 November 2015).

Table 1. Simulation runs for the two event cases with the models Ah and Aop, for the grids G1 (1 km horizontal resolution) and G2 (2 km horizontal resolution).

\begin{tabular}{llll}
\hline $\begin{array}{l}\text { Models } \\
\text { Grid }\end{array}$ & Ah & Ah & Aop \\
\hline Meteorological & COSMO-LEPS & COSMO-LEPS & COSMO-LEPS \\
forcing & deterministic run & deterministic run & deterministic run \\
& COSMO-LEPS & & COSMO-LEPS \\
& 16 members & & 16 members \\
\hline
\end{tabular}

To infer the influence of the horizontal resolution, the Ah setup was run on two different computational grids: the grid G2 (which is currently used for the operational Aop), characterized by $2 \mathrm{~km}$ horizontal resolution and a minimum bathymetry of $4 \mathrm{~m}$, and the grid G1, with $1 \mathrm{~km}$ horizontal resolution and a minimum bathymetry of $1 \mathrm{~m}$. The events have been simulated also using the Aop model on the G2 grid. It is thus possible to compare the differences between the effects on the grid resolution only, and the effects on the two different model configurations separately.

Additionally, in order to evaluate the meteorological forcing effect, the Aop and Ah models have been run in ensemble mode, forced by the Arpae 16-members COSMO-LEPS ensemble system (Montani et al., 2011). All test runs have a forecast length of $+96 \mathrm{~h}$. The list of simulations presented in this study are summarized in Table 1.

\section{Results and discussion}

The outputs of the model Ah runs on the two different grids G1 and G2 are shown in Fig. 3 for the November 2015 event. All runs start at 20 November 2015, 00:00 UTC with a forecast length of $+96 \mathrm{~h}$ and are forced with the atmospheric fields provided by the deterministic run of COSMOLEPS model, characterized by $7 \mathrm{~km}$ horizontal resolution. The comparison between the two runs with grid G1 and G2 does not show significant differences for the grid points close to Ancona and Vieste and the effect of the horizontal resolu- tion on the model output is barely evident. This can be explained by the fact that the typical length scale of sea level variations due to tides and storm surge is larger than the grid resolution and therefore the differences are not expected to be huge.

The outputs are also compared with sea-level data retrieved from the Italian ISPRA-RMN tide gauge network for Ancona and Vieste tide-gauge stations (see also map in Fig. 1): in this case, Ancona is strongly affected by a storm surge during the event, while Vieste is not affected by the storm and presents a dominant tidal cycle. It is clear that, for both grids G1 and G2, the surge in the north-central part of the Adriatic is not correctly reproduced by the models, which underestimates the sea level in Ancona of about $0.3 \mathrm{~m}$ at the surge peak. In Vieste, the tidal oscillation is in good agreement with observed data. A correct astronomical tide modelling, but a missing storm surge component in the sea level forecast is confirmed comparing simulations against the data recorded by the other available tide gauges on the Italian Adriatic side (not shown here).

In Fig. 3, the sea level forecasted by the model Ah run on the grid $\mathrm{G} 2$ can be compared with the sea level forecasted by the model Aop on the same grid. It is evident that the tidal trend of the model Aop is shifted respect to the Ah model and to the data, while the trend of the model Ah is correct. The comparison between the two models show that 5 astronomical components do not seems sufficient to correctly reproduce tides. 

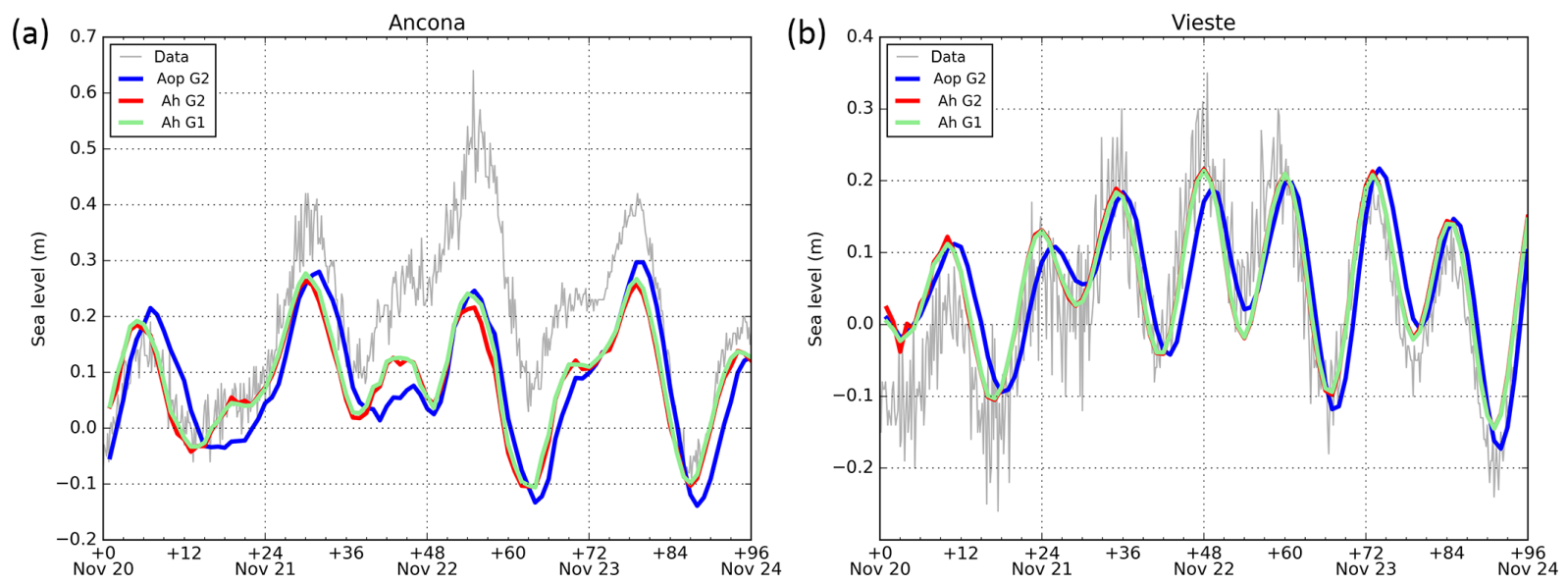

Figure 3. 21 November 2015 storm. Measured sea level in Ancona and Vieste (grey line) and forecasted sea level with models Ah (with grids G1 and G2) and Aop with grid G2.

(a)

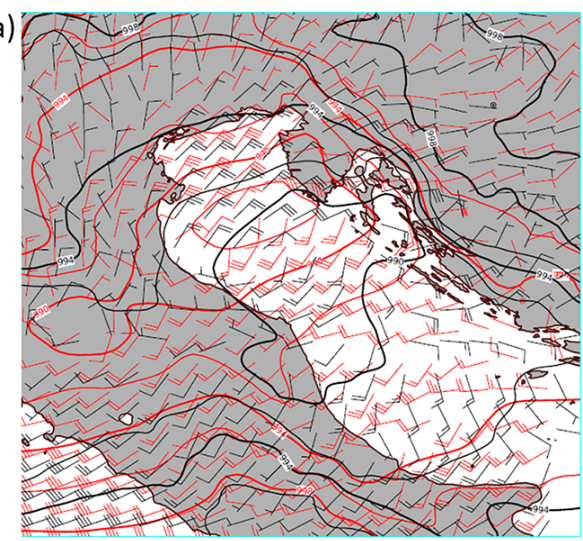

(b)

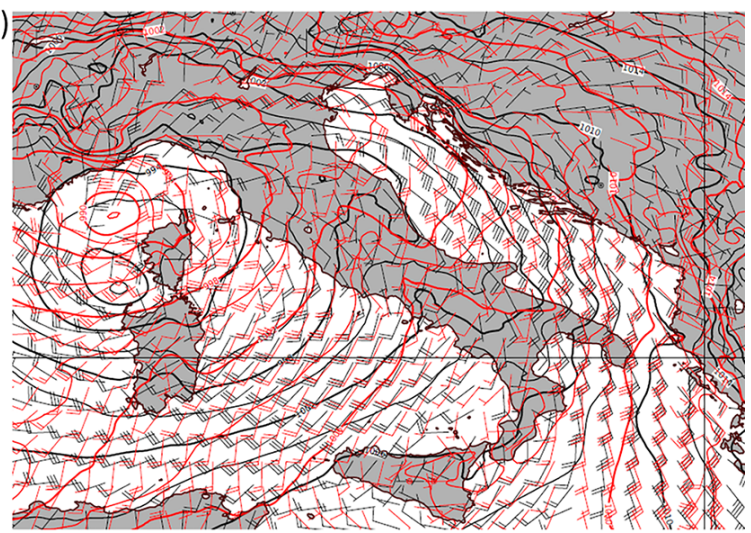

Figure 4. Comparison of the ECMWF analysis (black) and the deterministic run of COSMO-LEPS (red) after $+48 \mathrm{~h}$ forecast. Regarding the November 2015 event (a), the position of the minimum of the mean sea level pressure at 22 November 2015, 00:00 is shifted towards north: in the north-central part of the Adriatic basin, the forecasted winds blow from the earth towards the sea preventing the storm surge, while in the ECMWF analysis, the location of the minimum allows the winds to turn from south-west to south-east along the coasts near Ancona. Regarding the February 2016 event (b), the difference in the position of the minimum of the mean sea level pressure at 29 February 2016, 00:00 introduces discrepancies in the wind direction over the whole Adriatic basin: from the ECMWF analysis, the scirocco winds keep blowing along the Adriatic basin, while the forecasted winds cross the Adriatic blowing north.

In order to verify the influence of the meteorological forcing in the sea level forecasting, the models Aop and Ah have been run in ensemble mode with respectively grid $\mathrm{G} 2$ and G1, forced by the output fields of the 16 members COSMOLEPS suite. Since the atmospheric forcing plays a significant role for the sea level modelling, it is important to take into account that the meteorological forecast presents some discrepancies with the real situation in both cases. By comparing the fields of COSMO-LEPS with the ECMWF analysis (see Fig. 4) for the event of November 2015, the minimum of pressure located on the Adriatic sea is shifted towards northeast in the forecast, which leads to different wind speeds and pattern along the central-northern Adriatic coasts. The same comparison for the 2016 event shows that the forecasts of the ensemble runs start drifting from the analysis starting at 29
February, 00:00 and that the different location of the minimum of pressure on the Mediterranean near Corsica leads to a different rotation of winds in the central Mediterranean and along the Adriatic basin.

The ensemble mean on the whole Adriatic basin and the ensemble spread (defined as the standard deviation of a variable with respect to the ensemble mean) of the wind speed and mean sea level pressure is in general agreement with the spread of the COSMO-LEPS system and it is shown in Fig. 5 for the two storm events, together with the mean of the same fields of the deterministic run of COSMO-LEPS and of the ECMWF analysis.

In both cases, the storm surge component is not reproduced correctly. The November 2015 event interested mainly the northern part of the basin, as it can be seen by compar- 
(a)

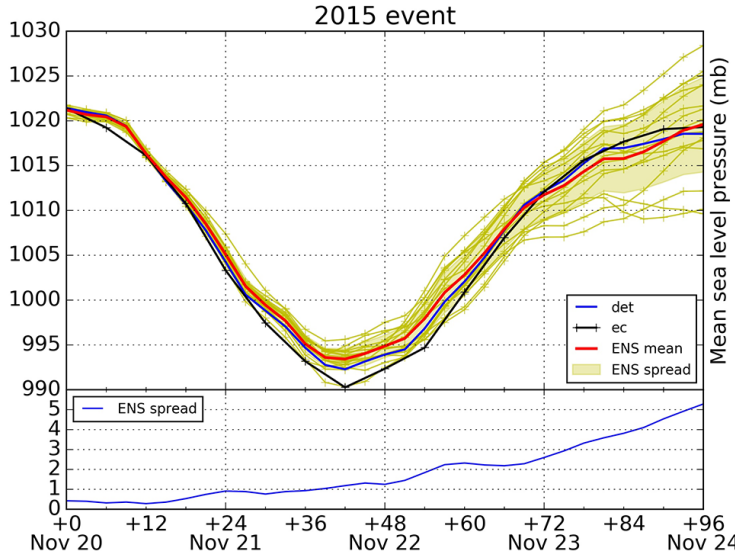

(c)

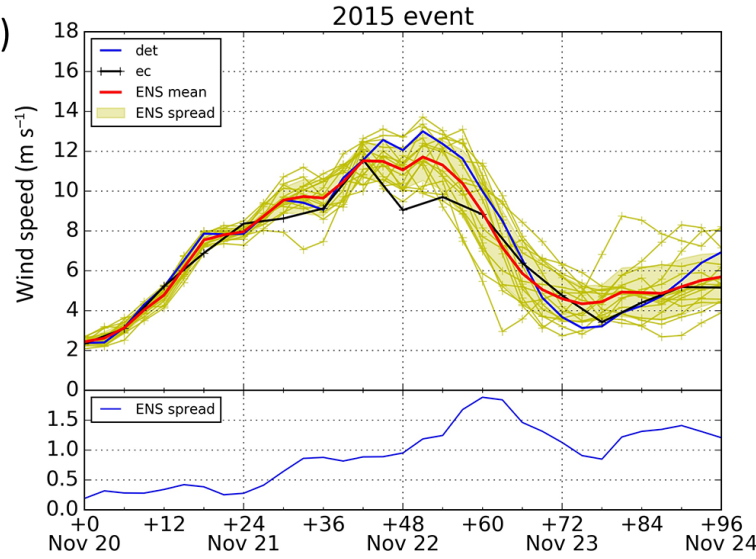

(b)

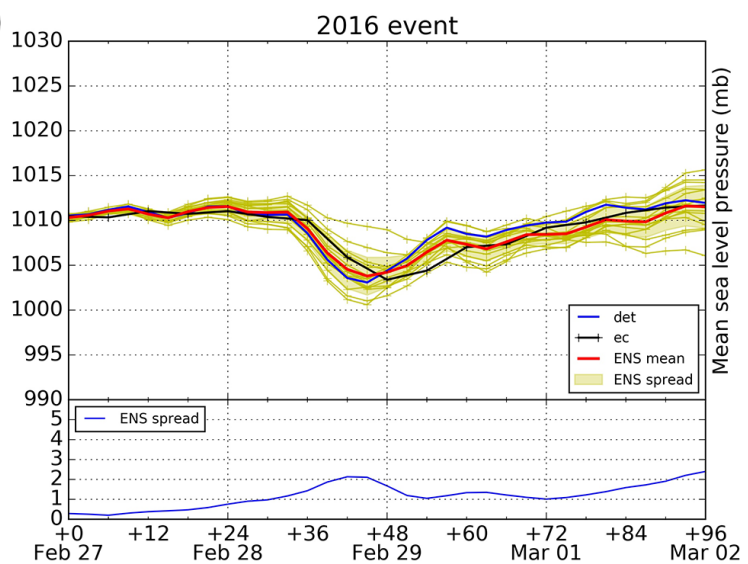

(d)

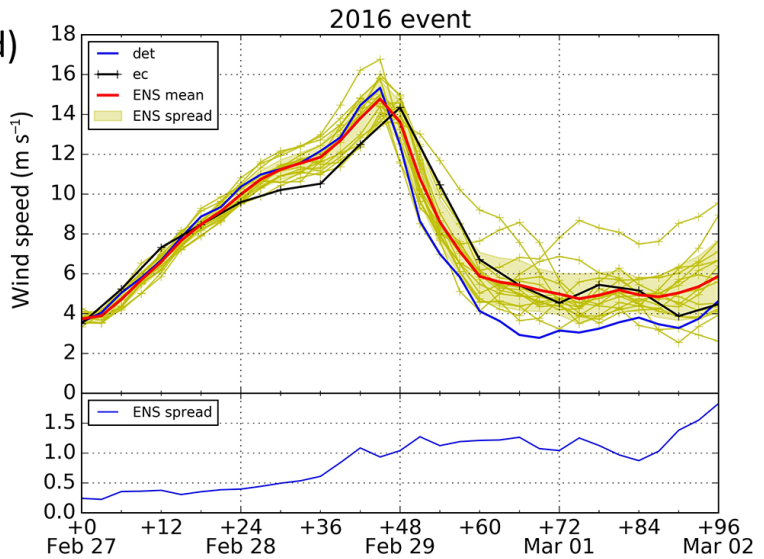

Figure 5. Mean values mean sea level pressure $(\mathbf{a}, \mathbf{b})$ and wind speed $(\mathbf{c}, \mathbf{d})$ over the Adriatic basin for for the events of November 2015 (a, c) and of February 2016 (b, d). The ensemble means are compared with the ECMWF analysis (black). The ensemble spread for each variable is shown on the bottom part of each figure. The ensemble mean is plotted in red, while each member output is shown in yellow. The deterministic run is shown in blue. The shaded area envelops the ensemble mean (solid red line) \pm the ensemble spread.

ing the tide gauge data (in Fig. 6) of Ancona and Vieste. The comparison with sea-level data at the Ancona station for the 2015 event shows that the storm surge component of sea level is highly underestimated and that the spread in the forecasted sea level, generated by the meteorological ensemble, is not sufficient to include the measurements. However, it is important to take into account that this event was not correctly reproduced by the meteorological forecast and that this discrepancy contributes to the sea level error. The maximum forecasted sea level spread is computed for selected stations for the November 2015 event in Table 2: it increases from south to north to reach about $0.1 \mathrm{~m}$, but it remains quite low respect to the storm surge, that can be estimated of about $0.25-0.3 \mathrm{~m}$ in Ancona from tide-gauge data (Fig. 6, upper panels).

The event of February 2016 generated a small storm surge in the northern Adriatic basin (see Fig. 6, lower panels). Despite the moderate intensity of the event, the ensemble predictions for this case give a higher sea level spread than for the November 2015 event: the sea level ensemble spread has higher values not only for selected locations (see Table 3), but also considering the mean on the whole basin and coasts (see Fig. 7). Also for this case, the sea level trend is not correctly reproduced by the forecast, and it seems overestimated for both Ancona and Vieste (see Fig. 6, lower panels).

The sea level spread of the two models Ah and Aop does not present significant differences, as it can be seen also in Fig. 7, where the sea level spread for the whole Adriatic basin, and for the coastal grid cells (defined as the cells connected to a land cell) is shown for the two events. The maximum spread for the whole surface basin is about $2 \mathrm{~cm}$ for both events and it occurs simultaneously with the storm peaks. The spread for the coastal region is higher than the one for the whole Adriatic basin, and it is of about $3 \mathrm{~cm}$ for the 2015 event case and of about $4 \mathrm{~cm}$ for the 2016 event case. Both models have a similar variability to the meteorological ensemble forcing (Fig. 7), but a different performance, especially for the February 2016 event (Fig. 6): the different model parametrization might contribute to the missing storm 
(a)

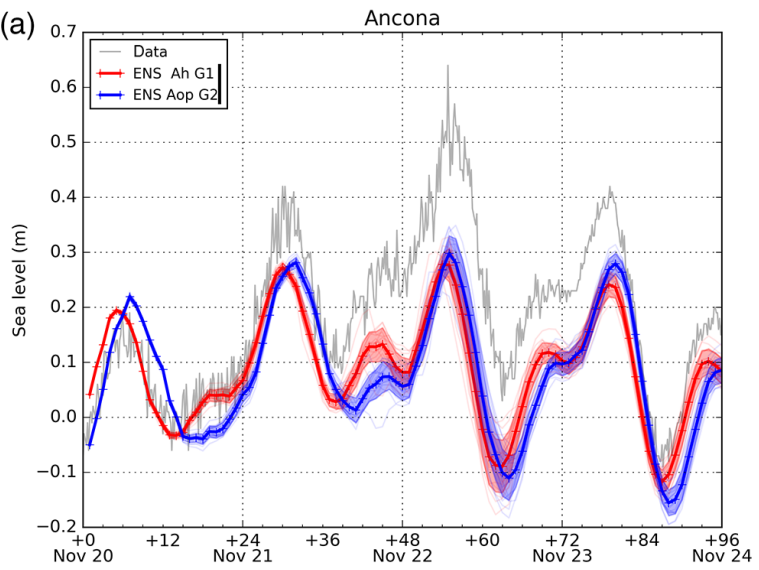

(b)

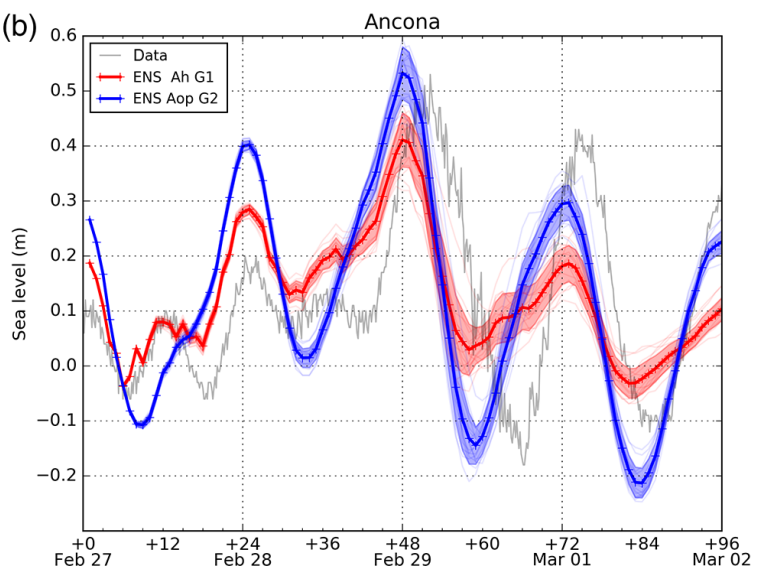

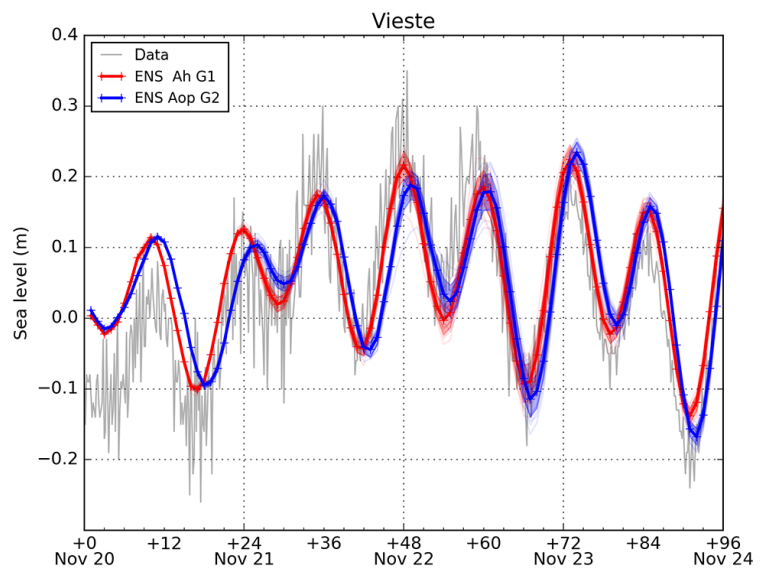

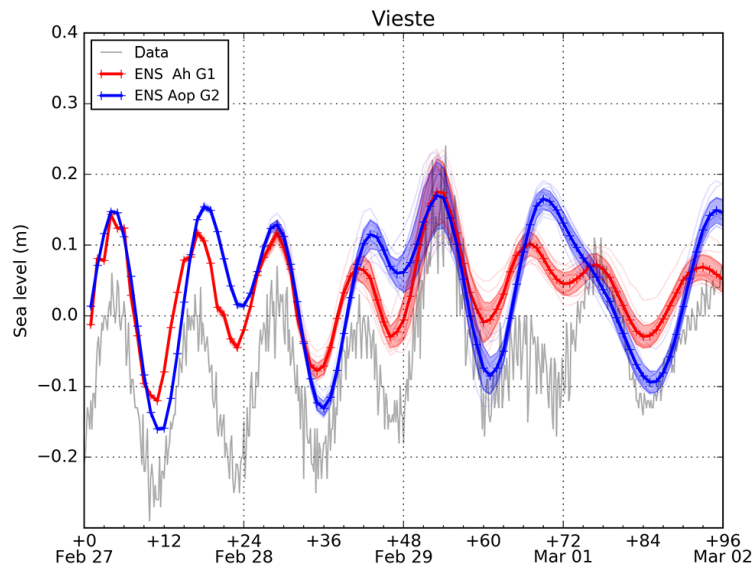

Figure 6. Comparison of the sea level data (grey line) recorded in Ancona and Vieste with the ensemble output for models Aop (in blue) and $\mathrm{Ah}$ (in red) for the 2015 event (a) and for the 2016 event (b). The solid line represent the ensemble mean and the shaded area the ensemble spread.

Table 2. Maximum sea level spread for selected tide-gauge stations for the November 2015 event.

\begin{tabular}{lll|ll}
\hline \multirow{2}{*}{ November 2015 } & \multicolumn{2}{c|}{ Ah model } & \multicolumn{2}{c}{ Aop model } \\
\cline { 2 - 5 } & $\begin{array}{l}\text { Forecast lead } \\
\text { time (h) }\end{array}$ & $\begin{array}{l}\text { Maximum } \\
\text { spread (m) }\end{array}$ & $\begin{array}{l}\text { Forecast lead } \\
\text { time (h) }\end{array}$ & $\begin{array}{l}\text { Maximum } \\
\text { spread (m) }\end{array}$ \\
\hline Venezia & +53 & 0.11 & +52 & 0.12 \\
Trieste & +57 & 0.09 & +57 & 0.10 \\
Ancona & +61 & 0.05 & +60 & 0.05 \\
San Benedetto del Tronto & +57 & 0.05 & +57 & 0.05 \\
Ortona & +58 & 0.04 & +58 & 0.04 \\
Vieste & +66 & 0.03 & +65 & 0.03 \\
\hline
\end{tabular}

surge modelling, but its influence must be carefully investigated.

\section{Conclusions}

In order to investigate the possible causes of the storm surge underestimation, a study was carried out testing two different ROMS model parametrization, Ah and Aop, to reproduce two marine storms that occurred during the winter 20152016 in the central-northern part of the Adriatic Sea. The tests carried out included the comparison of two runs of the model with two different horizontal resolution (1 and $2 \mathrm{~km}$ ) and the comparison of two runs with two different model parametrization on the same grid. An additional test was carried out taking into account the uncertainty of the meteoro- 
(a)

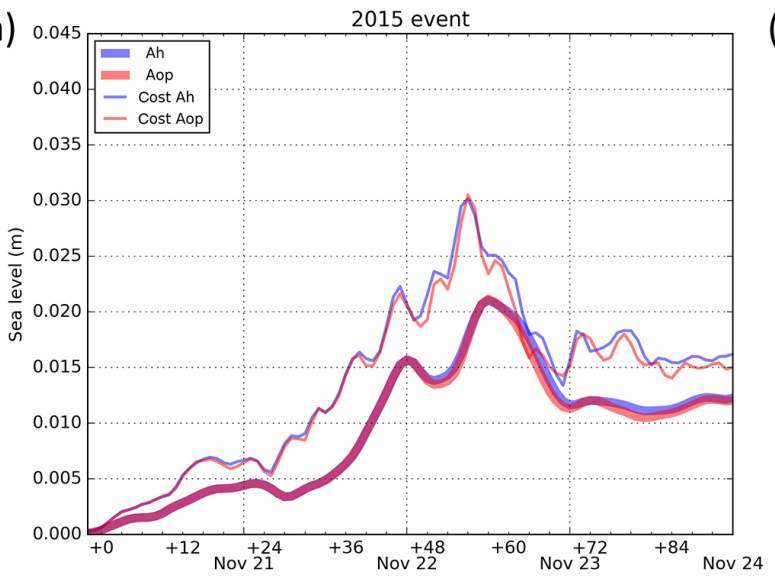

(b)

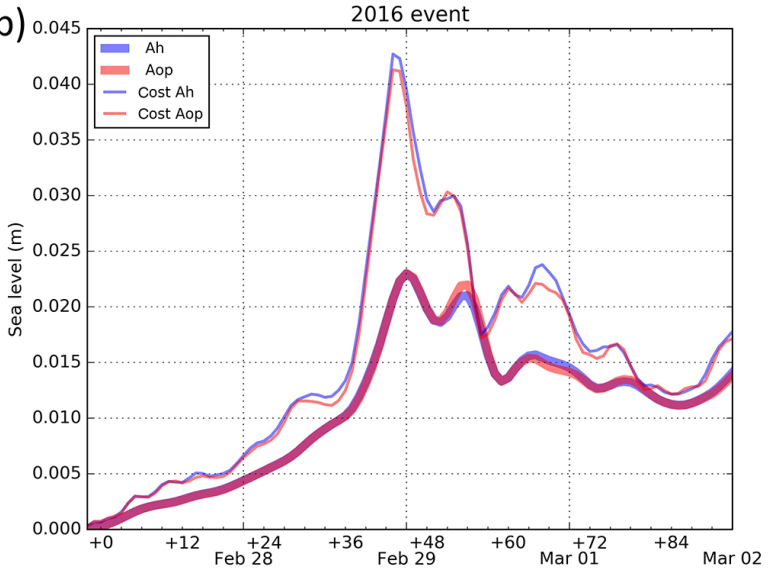

Figure 7. Ensemble spread for sea level for the whole basin (thick lines) and for coastal grid cells (thin lines) for the 2015 event (a) and for the 2016 event (b).

Table 3. Maximum sea level spread for selected tide-gauge stations for the February 2016 event.

\begin{tabular}{lll|ll}
\hline \multirow{2}{*}{$\begin{array}{l}\text { February 2016 } \\
\text { Location }\end{array}$} & \multicolumn{2}{c|}{ Ah model } & \multicolumn{2}{c}{ Aop model } \\
\cline { 2 - 5 } & $\begin{array}{l}\text { Forecast lead } \\
\text { time (h) }\end{array}$ & $\begin{array}{l}\text { Maximum } \\
\text { spread (m) }\end{array}$ & $\begin{array}{l}\text { Forecast lead } \\
\text { time (h) }\end{array}$ & $\begin{array}{l}\text { Maximum } \\
\text { spread (m) }\end{array}$ \\
\hline Venezia & +47 & 0.17 & +47 & 0.17 \\
Trieste & +47 & 0.18 & +47 & 0.19 \\
Ancona & +55 & 0.07 & +54 & 0.07 \\
San Benedetto del Tronto & +52 & 0.04 & +52 & 0.04 \\
Ortona & +52 & 0.04 & +52 & 0.04 \\
Vieste & +53 & 0.05 & +53 & 0.05 \\
\hline
\end{tabular}

logical forcing by forcing the ocean model with meteorological ensemble fields.

The first test that compares the runs with two different grids highlight that the model horizontal resolution does not seem to be an important factor for these type of events. From the test that compares the two model parametrizations, it is possible to conclude that the configuration differences do not account for the missing storm surge, but that the tidal forcing is not correctly reproduced with only 5 tidal components.

The meteorological forcing is a critical factor and, at least for the 2015 marine event, the meteorological forecast present some discrepancies respect to the observed conditions. As direct consequence, the oceanographic models hardly reproduce the sea level and the corresponding sea level spread of the oceanic ensemble seems to be inadequate for both cases. Despite the meteorological ensemble runs show a generally adequate meteorological spread in terms of the wind and pressure when averaged over the entire basin, the difference in the position of the minimum of the mean sea level pressure between the ensemble and the analysis may be responsible for the discrepancies in the sea level prediction at the considered locations.
It is important to be aware that the meteorological forcing is not the only cause for the missing surge in the northern Adriatic sea. In order to correctly forecast storm surges, other possible sources of error that should be investigated carefully are the forcing imposed at the southern boundary, the horizontal resolution of the meteorological forcing and the model parametrization.

Data availability. Wind and atmospheric data, the tide gauge data of Porto Garibaldi and the wave data of Arpae Nausicaa wave buoy are public and are stored in the Arpae database, accessible with the web interface http://www.smr.arpa.emr.it/dext3r. The sea level data from the other tide gauges are public and provided by the Italian RMN network and can be found at http://www.mareografico.it, where it is possible to select the stations and data of interest.

Competing interests. The authors declare that they have no conflict of interest.

Acknowledgements. We thank Davide Cesari and the collegues of Arpae-SIMC for the useful discussions. 
Edited by: M. M. Miglietta

Reviewed by: A. Benetazzo and one anonymous referee

\section{References}

Benetazzo, A., Carniel, S., Sclavo, M., and Bergamasco, A.: Wave-current interaction: Effect on the wave field in a semi-enclosed basin, Ocean Model., 70, 152-165, doi:10.1016/j.ocemod.2012.12.009, 2013.

Chiggiato, J. and Oddo, P.: Operational ocean models in the Adriatic Sea: a skill assessment, Ocean Sci., 4, 61-71, doi:10.5194/os-461-2008, 2008.

Egbert, G. D. and Erofeeva, Y. S.: Efficient Inverse Modeling of Barotropic, Ocean Tides, J. Atmos. Ocean. Tech., 19, 183204, doi:10.1175/1520-0426(2002)019<0183:EIMOBO>2.0.CO;2, 2002.

Haidvogel, D. B., Arango, H., Budgell, W. P., Cornuelle, B. D., Curchitser, E., Di Lorenzo, E., Fennel, K., Geyer, W. R., Hermann, A. J., Lanerolle, L., Levin, J., McWilliams, J. C., Miller, A. J., Moore, A. M., Powell, T. M., Shchepetkin, A. F., Sherwood, C. R., Signell, R. P., Warner, J. C., and Wilkin, J.: Ocean forecasting in terrain-following coordinates: formulation and skill assessment of the Regional Ocean Modeling System, J. Comp. Phys., 227, 3595-3624, doi:10.1016/j.jcp.2007.06.016, 2008.

Harley, M. D., Valentini, A., Armaroli, C., Perini, L., Calabrese, L., and Ciavola, P.: Can an early-warning system help minimize the impacts of coastal storms? A case study of the 2012 Halloween storm, northern Italy, Nat. Hazards Earth Syst. Sci., 16, 209-222, doi:10.5194/nhess-16-209-2016, 2016.

HAZADR final publication: a cross-border initiative to protect the Adriatic Coasts from oil spill, Pagina soc. coop. a rl., Italy, ISBN 978-88-7470-483-5, www.hazadr.eu/publications, 2015.

Montani, A., Cesari, D., Marsigli, C., and Paccagnella, T.: Seven years of activity in the field of mesoscale ensemble forecasting by the COSMO-LEPS COSMO system: main achievements and open challenges, Tellus A, A 63, 605-624, doi:10.1111/j.16000870.2010.00499.x, 2011.
Oddo, P., Adani, M., Pinardi, N., Fratianni, C., Tonani, M., and Pettenuzzo, D.: A nested Atlantic-Mediterranean Sea general circulation model for operational forecasting, Ocean Sci., 5, 461-473, doi:10.5194/os-5-461-2009, 2009.

Raicich, F.: On fresh water balance of the Adriatic Sea, J. Marine Syst., 9, 305-319, doi:10.1016/S0924-7963(96)00042-5, 1996.

Rodi, W.: Examples of calculation methods for flow and mixing in stratified fluids, J. Geophys. Res., 92, 5305-5328, doi:10.1029/JC092iC05p05305, 1987.

Russo, A., Coluccelli, A., Carniel, S., Benetazzo, A., Valentini, A., Paccagnella, T., Ravaioli, M., and Bortoluzzi, G.: Operational models hierarchy for short term marine predictions: the Adriatic Sea example, in: OCEANS-Bergen, 2013 MTS/IEEE Jun 10 (pp. 1-6), IEEE, 2013.

Shchepetkin, A. F. and McWilliams, J. C.: The regional ocean modelling system: a split-explicit, free-surface, topographyfollowing-coordinates ocean model, Ocean Modell., 9, 347-404, doi:10.1016/j.ocemod.2004.08.002, 2005.

Shchepetkin, A. F. and McWilliams, J. C.: Correction and commentary for "Ocean forecasting in terrain-following coordinates: Formulation and skill assessment of the regional ocean modeling system" by Haidvogel et al., J. Comp. Phys. 227, 3595-3624, J. Comp. Phys., 228, 8985-9000, doi:10.1016/j.jcp.2009.09.002, 2009.

Song, Y. and Haidvogel, D.: A semi-implicit ocean circulation model using a generalized topography-following coordinate system, J. Comput. Phys., 115, 228-44, doi:10.1006/jcph.1994.1189, 1994.

Warner, J. C., Armstrong, B., He, R., and Zambon, J. B.: Development of a coupled ocean-atmosphere-wave-sediment transport (COAWST) modeling system, Ocean Model., 35, 230-244, doi:10.1016/j.ocemod.2010.07.010, 2010.

Wilcox, D. C.: Reassessment of the scale-determining equation for advanced turbulence models, AIAA J., 26, 1299-1310, doi:10.2514/3.10041, 1988. 